\title{
Quality indicators for care of depression in primary care settings: a systematic review

Yelena Petrosyan ${ }^{1}$, Yeva Sahakyan ${ }^{2,3}$, Jan M. Barnsley ${ }^{1}$, Kerry Kuluski ${ }^{1,4}$, Barbara Liư ${ }^{5}$ and Walter P. Wodchis ${ }^{1,6,7^{*}}$

\begin{abstract}
Background: Despite the growing interest in assessing the quality of care for depression, there is little evidence to support measurement of the quality of primary care for depression. This study identified evidence-based quality indicators for monitoring, evaluating and improving the quality of care for depression in primary care settings.

Methods: Ovid MEDLINE and Ovid PsycINFO databases, and grey literature, including relevant organizational websites, were searched from 2000 to 2015. Two reviewers independently selected studies if (1) the study methodology combined a systematic literature search with assessment of quality indicators by an expert panel and (2) quality indicators were applicable to assessment of care for adults with depression in primary care settings. Included studies were appraised using the Appraisal of Indicators through Research and Evaluation (AIRE) instrument, which contains four domains and 20 items. A narrative synthesis was used to combine the indicators within themes. Quality indicators applicable to care for adults with depression in primary care settings were extracted using a structured form. The extracted quality indicators were categorized according to Donabedian's 'structure-process-outcome' framework.

Results: The search revealed 3838 studies. Four additional publications were identified through grey literature searching. Thirty-nine articles were reviewed in detail and seven met the inclusion criteria. According to the AIRE domains, all studies were clear on purpose and stakeholder involvement, while formal endorsement and usage of indicators in practice were scarcely described. A total of 53 quality indicators were identified from the included studies, many of which overlap conceptually or in content: 15 structure, 33 process and four outcome indicators. This study identified quality indicators for evaluating primary care for depression among adult patients.
\end{abstract}

Conclusions: The identified set of indicators address multiple dimensions of depression care and provide an excellent starting point for further development and use in primary care settings.

Keywords: Quality indicators, Major depression, Primary care, Quality of care, Quality assessment, Quality monitoring

\section{Background}

Depression is a common mental health problem for adults associated with decreased quality of life, productivity loss, family stress, increased utilization and cost of healthcare, and all-cause mortality [1-5]. The 12-month prevalence of depression is $4.7 \%$, with a lifetime prevalence of up to $16.6 \%$ in adults aged 18 years and older [6]. Previous research showed that the rate of depression was higher among older adults within hospitals (21\%) [1] and long-term care facilities (14\%) [7]. It is well established that depression in combination with a wide range

\footnotetext{
* Correspondence: walter.wodchis@utoronto.ca

${ }^{1}$ Institute of Health Policy, Management and Evaluation, University of

Toronto, 155 College Street, 4th Floor, Toronto, Ontario M5T 3M6, Canada

${ }^{6}$ Institute for Clinical Evaluative Sciences, Toronto, Canada

Full list of author information is available at the end of the article
}

of chronic conditions, including diabetes, cardiovascular disease, cancer and arthritis, can have a negative impact on the outcomes of these conditions [8-10].

Depressive disorders are most often managed by a primary care physician, unless the severity of depression is such that care is required from a specialist $[11,12]$. The Institute of Medicine defines primary care as the provision of integrated, accessible health care services by clinicians that are accountable for addressing a large majority of personal health care needs, developing a sustained partnership with patients, and practicing in the context of family and community' [13].

However, poor levels of detection, treatment and monitoring of depression have been highlighted in primary care settings [14]. Research shows that only a minority 
of patients with a depressive or anxiety disorder are treated in a primary care setting in accordance with clinical guidelines $[15,16]$. Literature suggests that people with any chronic condition frequently experience comorbid depressive symptoms that often go undetected [1, 17].

Assessment and monitoring of care quality has become crucial for healthcare systems worldwide to enhance the accountability of healthcare providers, to improve resource allocation efficiency, to identify and minimize medical errors and to improve health outcomes $[11,18]$. The Institute of Medicine defines quality of health care as 'the degree to which health services for individuals and populations increase the likelihood of desired health outcomes and are consistent with current professional knowledge' [19].

The assessment and monitoring of care quality can be achieved by using quality indicators which are based on standards of care and the best available evidence [20]. Data generated from these measures can be used to assess past performance, identify suboptimal practices and plan improvements. Donabedian has conceptualized the assessment of quality through examining the structures, processes and outcomes of care, and many quality indicators have been classified using this framework [21, 22].

The literature suggests that quality indicators should be evidence-based and be derived from the academic literature [20]. However, when scientific evidence is lacking, quality indicators can be defined by an expert panel of professionals by means of consensus techniques based on their experience. Evidence suggests that the systematic method of combining scientific evidence and expert opinion is the most rigorous way of developing quality indicators $[11,23]$.

Despite the growing interest in assessing the quality of care for depression, there has been little evaluation of the quality of care for depression in primary care settings [11, 24].

This project aimed (1) to identify evidence-based and valid quality indicators feasible for monitoring, evaluating and improving the quality of care for depression among adults over 18 years in primary care settings and (2) to critically appraise a set of identified quality indicators, using the AIRE (Appraisal of Indicators through Research and Evaluation) instrument. We conducted a systematic review to identify existing quality indicators for primary care for depression both in Canada and internationally.

\section{Methods}

\section{Search strategy}

A systematic literature search was conducted using Ovid MEDLINE and Ovid PsycINFO databases from January 2000 to June 2015, restricted to English articles of human studies, and when the participants consisted of adults over 18 years. The search terms used combined keywords and medical subject headings for depression and quality indicators. We used the following search terms to identify studies related to quality indicator development: 'performance indicator(s)/measure(s)', or 'quality indicator(s)/measure(s)', or 'benchmark', or 'report card' or 'quality of health care', or 'clinical guideline', or 'quality assurance'. To identify studies related to depression care, we used the following search terms: 'depression' or 'depressive disorder(s)'. The results from these two search steps were then combined (see Additional file 1).

In addition, we conducted a grey literature search to find information about quality indicator development initiatives that were not published in peer-reviewed journals. For that purpose, we searched available public repositories, including the National Quality Measures Clearinghouse (NQMC; http://www.qualitymeasures.ahrq.gov) and the National Quality Forum (NQF; http://www.qualityforum.org). Additionally, we looked for existing indicators at websites of major organizations involved in quality measurement and reporting of indicators for assessing the quality of depression care, including the RAND Health Corporation/Assessing Care of Vulnerable Elders (ACOVE), Canadian Mental Health Association (www.cmha.ca) and the online inventory maintained by the Center for Quality Assessment in Mental Health (www.cqaimh.org).

\section{Study selection}

The literature suggests the most rigorous way of developing quality indicators is through a systematic literature search combined with consensus techniques $[11,25,26]$. Where possible, quality indicators should be derived from scientific evidence $[11,26]$. The stronger the evidence, the stronger the potential benefit of quality indicators in terms of increase in the likelihood of achieving the best possible clinical outcomes [11, 26]. The main reasons for developing measures using consensus techniques include synthesizing accumulated expert opinion, enhancing decision-making, facilitating development of indicators where evidence alone is insufficient and identifying areas of care where there is controversy or uncertainty [11].

Therefore, articles were included for the purpose of this study if both of the following criteria were met:

- The study methodology combined a systematic literature search/development of indicators from clinical guidelines with assessment of quality indicators by an expert panel. 
- The identified quality indicators are applicable to the provision of primary care for depression among adult patients.

The identified titles were entered into a bibliographical database and duplicates were removed. One of the reviewers (YP) checked for the selected keywords in the title, abstract and subject heading of the articles. The resulting abstracts were included for full-text review. Two reviewers (YP and YS) independently conducted full-text review according to the inclusion criteria. Also, the references of selected articles were screened for other relevant studies that had not been found in the electronic search. The resulting set of articles was included in the methodological assessment process using the AIRE (Appraisal of Indicators through Research and Evaluation) instrument. The level of agreement between reviewers evaluating studies for inclusion and undertaking methodological assessments was assessed using kappa statistics [27].

Depression in this systematic review connotes major depression and dysthymia, since most clinical practice guidelines only address treatment of major depression [1]. Previous studies demonstrate that treatments for major depression also apply to dysthymic disorders [28-30]. Major depression disorder is defined 'as a period lasting at least 2 weeks characterized either by depressed mood (most of the day, nearly every day) and/or markedly diminished interest or pleasure in all, or almost all, activities (most of the day, nearly every day), during which a patient experiences five or more symptoms; the symptoms cause clinically significant distress or impairment in social, occupational, or other important areas of functioning; the episode is not attributable to the physiological effects of a substance or to another medical condition; and there has never been a manic episode or a hypomanic episode' [31, 32]. Dysthymic Disorder is 'characterized by a chronically depressed mood that occurs most of the day, more days than not, for at least 2 years' [31, 32].

\section{Methodological assessment}

We used the AIRE (Appraisal of Indicators through Research and Evaluation) instrument for the methodological assessment of the quality of the included articles [33]. It is a validated instrument that has been used previously in similar peer-reviewed studies [34-36]. The AIRE instrument contains 20 items, subdivided into four domains: (a) purpose, relevance and organizational context; (b) stakeholder involvement; (c) scientific evidence; and (d) additional evidence, formulation, and usage (see Additional file 2).

Two authors (YP and YS) independently appraised the included studies with the AIRE instrument. The AIRE instrument was applied to each completed set of quality indicators, because publications generally provided information about the development and scientific evidence of the total set of indicators instead of for each indicator separately [34-36]. Each item of the instrument has a score ranging from 1 to 4 with 1 -strongly disagree (confident that the criterion has not been fulfilled or no information was available); $2 / 3$-disagree/agree (unsure whether the criterion has been fulfilled); and 4-strongly agree (confident that the criterion has been fulfilled) [33].

Scores for each of the four domains were calculated by summing up all the scores of the individual items in a category and standardizing the total as a percentage of the maximum possible score for that domain. The maximum possible score for each domain was calculated by multiplying the maximum score per item (4) by the number of items in that domain $(5,3,3,9)$ and the number of appraisers (2). Similarly, the minimum possible score was calculated by using the minimum score per item (1).

The standardized category score is the total score per domain, minus the minimum possible score for that domain, divided by the maximum possible score, minus the minimum possible score $* 100 \%$. The standardized score ranges between 0 and $100 \%$, and a score of $50 \%$ and higher indicates a higher methodological quality for each domain of the instrument [35]. We conducted and reported this study according to the Preferred Reporting Items for Systematic Review and Meta-Analysis (PRISMA) statement (see Additional file 3). This review has not been registered with PROSPERO database.

\section{Data extraction}

A structured data extraction form was used to describe the selected studies with respect to the quality of depression care among adults over 18 years in primary care settings. The extraction information consisted of the title of the article; the publication date; summary of the indicator selection process; and description of indicators applicable to primary care for depression, including type, numerator and denominator of each quality indicator. The identified quality indicators were categorized according to Donabedian's 'structure-process-outcome' framework [37, 38].

Because we were examining indicators for use in primary and ambulatory care settings, we used a conceptual framework for primary care developed by Hogg et al. [39] to further categorize structural indicators. This framework includes 'structural' and 'performance' domains. The structural domain is divided into three components, including (1) the healthcare system, defined as the policies, stakeholders and factors at the 
system level that can influence primary care organizations and providers, (2) the practice context, defined as the factors at the community level that can influence the organization of the practice and the delivery of care, and (3) organization of the practice, defined as the structures and processes at the practice level.

\section{Results}

\section{Search results}

The systematic review identified 3838 potentially relevant studies from OVID MEDLINE and OVID PsycINFO (see Fig. 1). Four additional publications were identified through grey literature searching. After the review of titles/abstracts, 38 studies were deemed potentially relevant. One additional publication was included after tracking references. The full texts of these abstracts were obtained for review. Of these, 32 publications were excluded primarily because they failed to combine a systematic literature search or development of indicators based on clinical guidelines and expert panel opinion. Seven publications were included in the review (kappa $=0.91$; very good agreement) [40].

\section{Study characteristics}

The studies included in the review are summarized in Table 1 . The majority of included studies were obtained from the USA or the UK. All included articles [41-47] used a combination of literature review/development of quality indicators from clinical guidelines and some form of consensus technique (Delphi, Modified Delphi methodology, or 'constituency approach') to derive a final set of quality indicators. Out of seven studies included in this review, only one study reported development of quality indicators using a clinical practice guideline. This guideline was the Veterans Health Administration Department of Defence (VHA/DoD) clinical practice guideline for the management of major depressive disorder in adults with further critical appraisal of indicators using a Delphi approach [43].

Included studies differed in terms of target population and settings, but all of them provided quality indicators applicable to primary care settings. One of the studies was focused on assessing care for vulnerable elders with major depression or dysthymia in both outpatient and inpatient settings [41]. Five studies [42, 44-47] aimed to develop a set of evidence-based indicators for mental health services, including those for depression and delivered within primary care settings for adults. Another study aimed to develop quality indicators for the management of major depressive disorders among adults in primary care settings [43].

\section{Methodological quality}

The methodological quality of the included studies varied according to the AIRE instrument domains' scores (Table 2). All studies were clear on the first AIRE

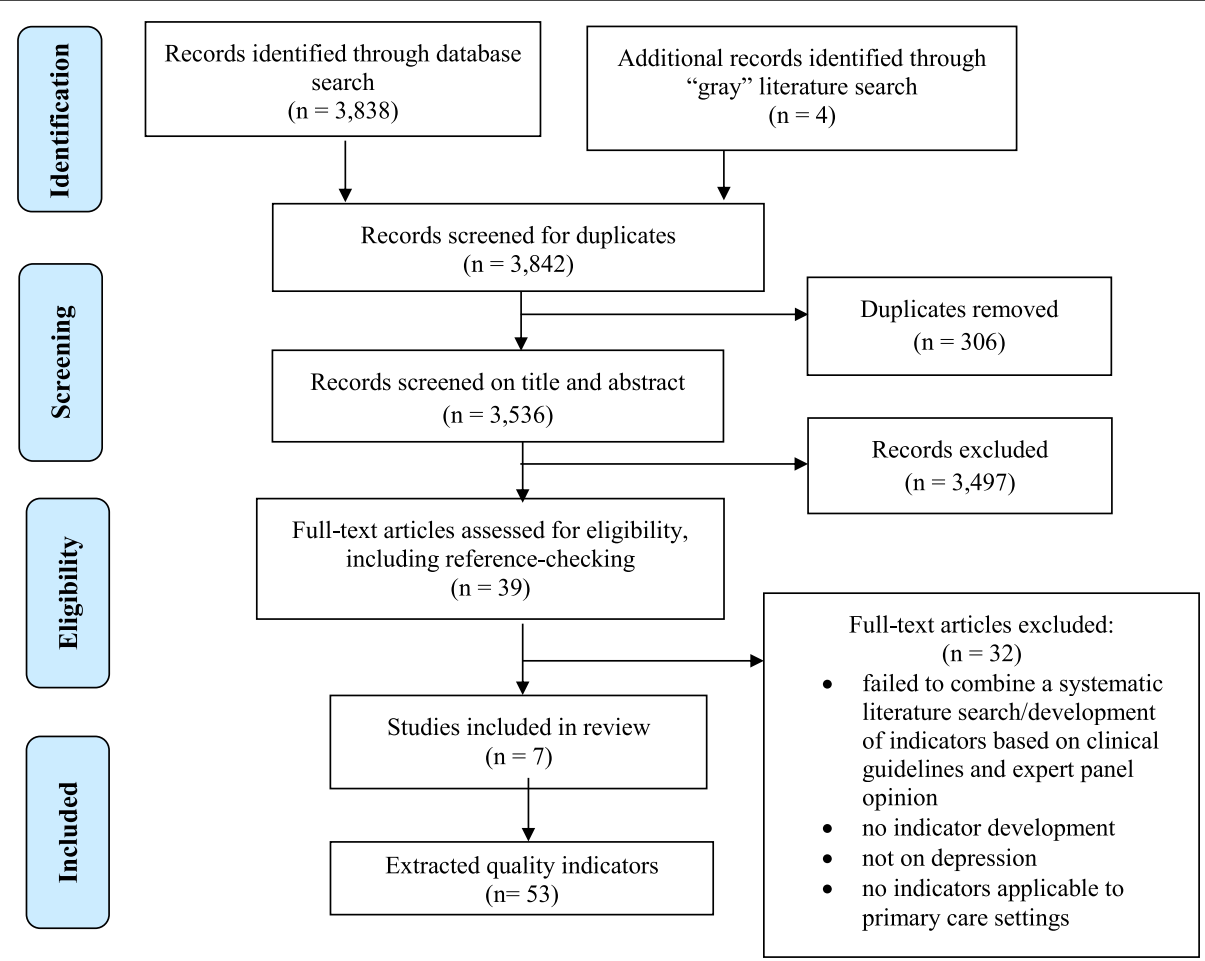

Fig. 1 Flow diagram for selection of studies for the review 
Table 1 Article characteristics

\begin{tabular}{|c|c|c|c|}
\hline First author/organization & Organization/initiative & Country/year & Study design \\
\hline Nakajima [41] & RAND/ACOVE & USA, 2007 & $\begin{array}{l}\text { Literature review for identifying candidate indicators; } \\
\text { RAND/UCLA Appropriateness methodology for critical } \\
\text { appraisal of indicators }\end{array}$ \\
\hline Hermann [42] & - & USA, 2004 & $\begin{array}{l}\text { Literature review for identifying candidate indicators; } \\
\text { Two-stage modified Delphi method for critical appraisal of indicators }\end{array}$ \\
\hline $\begin{array}{l}\text { Veterans Health Administration } \\
\text { Department of Defence [43] }\end{array}$ & VHA/DOD & USA, 2000 & $\begin{array}{l}\text { Development of candidate indicators from guidelines; } \\
\text { Delphi methodology for critical appraisal of indicators }\end{array}$ \\
\hline Hermann [44] & OECD HCQI Project & OECD, 2006 & $\begin{array}{l}\text { Candidate indicators were drawn from OECD member } \\
\text { countries quality initiatives; } \\
\text { Modified Delphi methodology for critical appraisal of indicators }\end{array}$ \\
\hline $\begin{array}{l}\text { Canadian Mental Health } \\
\text { Association (CMHA) [45] }\end{array}$ & CMHA, CEQM project & Canada, 2012 & $\begin{array}{l}\text { Literature review for identifying candidate indicators; } \\
\text { 3-phase consensus-building methodology for critical appraisal of indicators }\end{array}$ \\
\hline Shield [46] & - & UK, 2003 & $\begin{array}{l}\text { Literature review for identifying candidate indicators; } \\
\text { Two-round Delphi methodology for critical appraisal of indicators }\end{array}$ \\
\hline Worrall [47] & - & UK, 2002 & $\begin{array}{l}\text { Mix of literature review and stakeholder workshops for i } \\
\text { dentifying candidate indicators; } \\
\text { Consensus methodology for critical appraisal of indicators }\end{array}$ \\
\hline
\end{tabular}

RAND Research and Development, ACOVE Assessing the Care of Vulnerable Elders Project, VHA/DOD Veterans Health Administration Department of Defence, $O E C D$ Organisation for Economic Co-operation and Development, CMHA Canadian Mental Health Association

instrument domain, demonstrating good evidence for describing the purpose of quality indicator development and the patient population to whom they were meant to apply, as well as presenting the indicator selection criteria and applicability of measures. Two studies $[42,43]$ received low scores for the second AIRE domain due to lack of information regarding the relevant stakeholders' involvement at some stage of the indicator development process. The studies included in the present systematic review mainly represent the views of mental health administrators and clinicians, including psychiatrists and psychologists, as well as health service researchers and social workers. Only one included study represents patients' perspectives on quality of depression care in developing quality indicators [47].

According to the Institute of Medicine (IOM), the appropriate high-level leadership, organization or experts, rather than those who developed the measure, should review and endorse measures of quality intended for population health improvement [48]. To this end, we identified which of the extracted quality indicators were endorsed by the National Quality Forum (NQF) and which were not. The National Quality Forum (NQF) is a voluntary not-for-profit membership organization created to develop and implement a national strategy for healthcare quality measurement and reporting. NQF evaluates measures against standardized measure evaluation criteria, including (1) importance to measure and report, (2) scientific acceptability of measure properties, (3) feasibility, (4) usability and use and (5) requirements for related and competing measures. NQF-endorsed consensus standards are now widely viewed as the 'gold standard' for measurement of healthcare quality, and NQF-endorsed measures are deemed to be evidencebased and valid [49].

The scientific evidence for the quality indicator development process was scarcely described in three articles

Table 2 AIRE instrument score

\begin{tabular}{|c|c|c|c|c|}
\hline \multirow[t]{2}{*}{ First author } & \multicolumn{4}{|c|}{ AIRE instrument-standardized score (\%) } \\
\hline & $\begin{array}{l}\text { Purpose, relevance and } \\
\text { organizational context }\end{array}$ & $\begin{array}{l}\text { Stakeholder } \\
\text { involvement }\end{array}$ & $\begin{array}{l}\text { Scientific } \\
\text { evidence }\end{array}$ & $\begin{array}{l}\text { Additional evidence, } \\
\text { formulation and usage }\end{array}$ \\
\hline Nakajima [41] & 88 & 73 & 94 & 82 \\
\hline Hermann [42] & 78 & 55 & 61 & 75 \\
\hline VHA/DOD [43] & 73 & 54 & 55 & 78 \\
\hline Hermann [44] & 78 & 83 & 60 & 72 \\
\hline CMHA [45] & 76 & 72 & 61 & 54 \\
\hline Shield [46] & 90 & 83 & 78 & 60 \\
\hline Worrall [47] & 65 & 66 & 65 & 60 \\
\hline
\end{tabular}


[43-45]. Finally, most studies received high scores on the domain 'Additional evidence, formulation, usage'; some initiatives reported numerator and denominator definitions, while others only provided the list of indicators. In the included studies, the quality indicators were appraised for different criteria, including importance of the quality indicators to be scientifically sound, valid, reliable and acceptable. Feasibility of data collection was assessed in four studies [42-44, 47]. In most studies, information regarding the piloting of indicators in practice and instructions for presenting and interpreting results were scarcely described.

\section{Quality indicators}

Quality indicators were extracted only if they were relevant to the provision of primary care for depression. For the purpose of this study, the target population was defined as adults over 18 years with a diagnosis of major depression or dysthymia. The literature suggests that treatment of major depressive disorder also applies for dysthymia disorder [28-30, 50], and for the most part, quality indicators related to the management of major depression apply to that of dysthymia.

The identified quality indicators were organized according to Donabedian's 'structure-process-outcome' framework [21, 38]. Structure indicators refer to settings where depression care is delivered, including adequate facilities, qualification of care providers or administration structure. Process indicators examine how depression care has been provided in terms of appropriateness, acceptability, completeness or competency. Outcome indicators refer to the end points of depression care, such as improvement in function or recovery [38].

A total of 53 quality indicators were identified from the included studies, many of which overlap conceptually or in content: 16 structure, 33 process and four outcome indicators (Table 3). Several quality indicators were represented in multiple articles; this might be a reflection of the attention to these areas of depression care in primary care settings.

The structure indicators were derived from two articles that aimed to develop indicators to evaluate primary care services for people with depression [46, 47]. They were categorized into two main domains: (1) structural, including quality improvement process, resources and technical provisions, and practice integration and (2) performance, including access to care, and organizational structure and dynamics [39].

Process indicators represent the way depression care is delivered, encompassing both clinical effectiveness and interpersonal effectiveness. The identified process indicators have been categorized into the following common groups: depression screening and detection; screening for suicidal ideation; assessment for comorbid conditions; initiating, continuing and monitoring depression treatment; antidepressant choice; and depression follow-up, as well as patient/caregiver education, patient-provider relationship and shared decision-making. We identified a few 'negative' or 'do not do' process indicators, including the use of anticholinergic antidepressants, tertiary amine tricyclics, MAO inhibitors or benzodiazepines as firstor second-line therapy in older adults with depression $[41,42,44]$.

The outcome indicators identified in this study have been developed by the National Quality Measures Clearinghouse (NQMC) and published by the Agency for Healthcare Research and Quality (AHRQ) [51-54] and endorsed by the National Quality Forum (NQF). They focused on response to treatment and achieving remission at 6 or 12 months of depression treatment.

\section{Discussion and conclusions}

The current systematic review identified 53 quality indicators for evaluating primary care for depression. They assess multiple aspects of primary care for depression, including organizational and clinical aspects of depression care, as well as policy importance. All included studies used a rigorous method of developing quality indicators $[11,25,26]$ by combining a systematic literature search with appraisal of candidate indicators using expert panel opinion. Despite the importance of depression care, relatively few of the identified quality indicators are formally endorsed as legitimate measures of quality of depression care.

One of the important aspects when developing indicators is involvement of different stakeholders with different perspectives on quality of care. The studies included in the present systematic review mainly represent the views of mental health administrators and clinicians, including psychiatrists and psychologists, as well as health service researchers and social workers. Only one included study represented patients' perspectives on quality of depression care in developing quality indicators [47]. In the process of developing quality indicators, it is recommended to include the perspectives of all potential end users including patients, their family caregivers, health professionals and managers [55]. There is a particular need to ensure that indicators reflect what matters most to patients.

Most quality indicators identified in this study focused on the structure or process of primary care for depression. The identified structure indicators have been categorized into structural and performance domains. The identified process indicators measure the activities and tasks in primary care for depression, including health providers' activities in screening and detecting depression and initiating, implementing and monitoring depression treatment, as well as interacting with patients. 


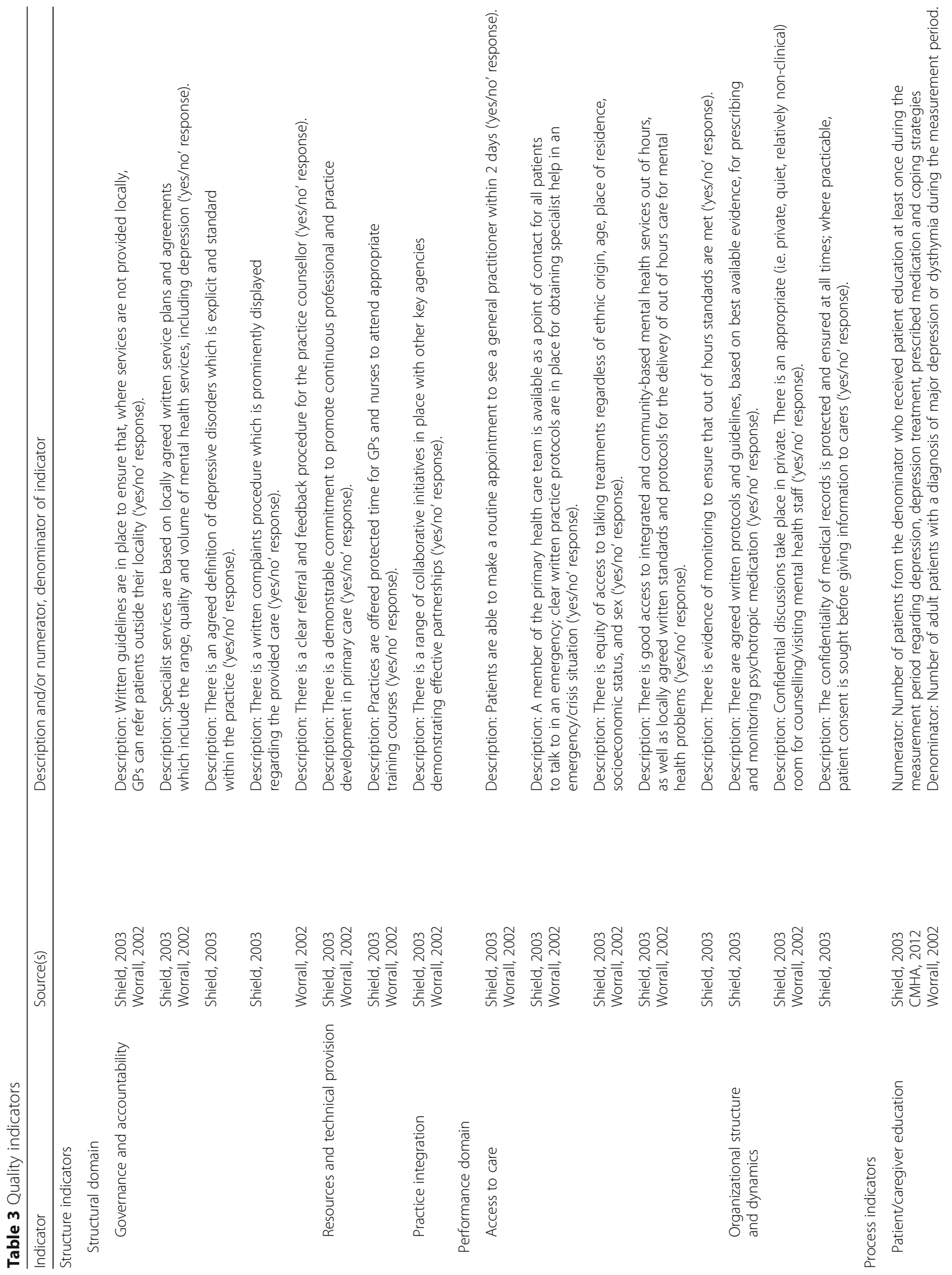




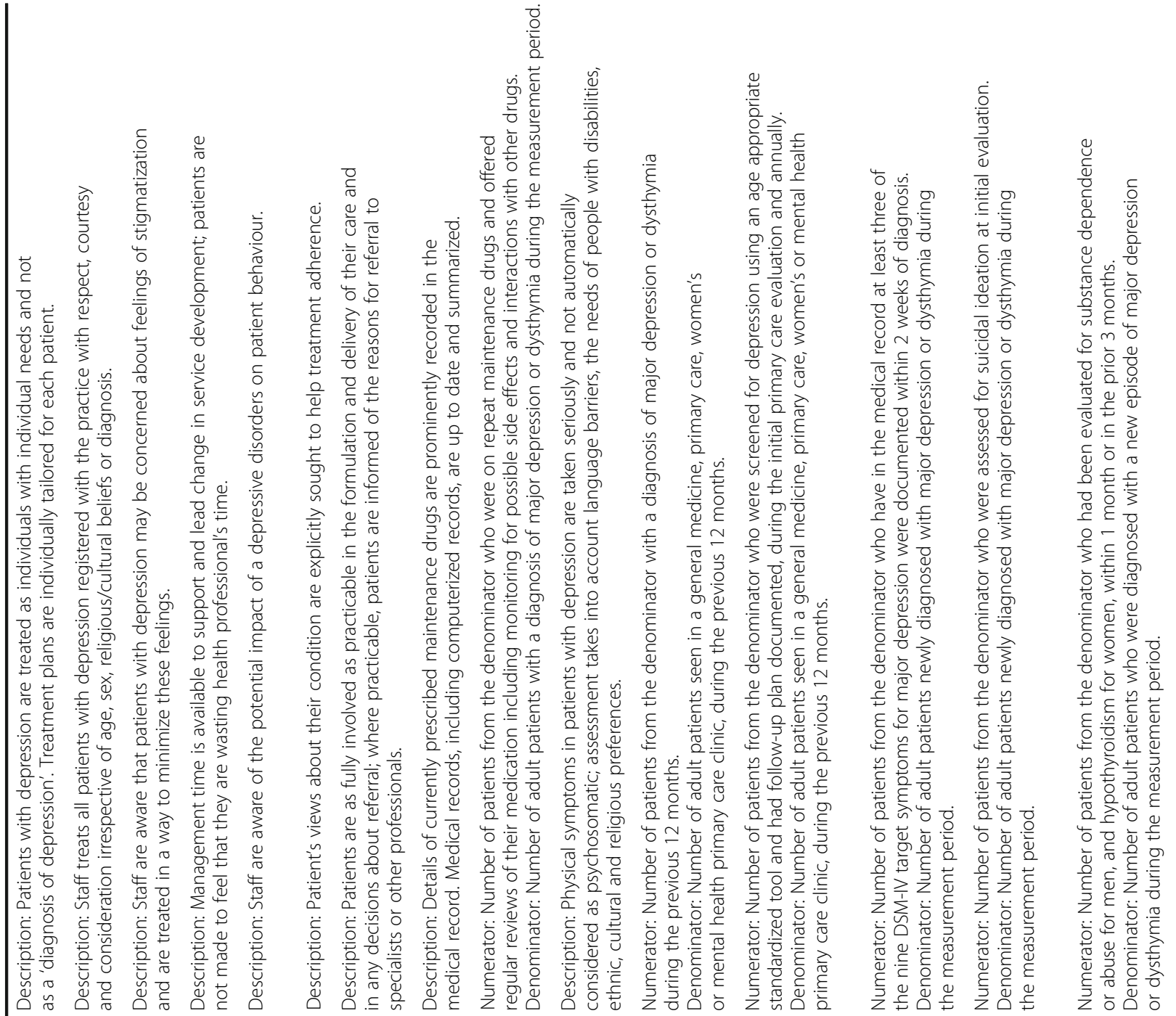

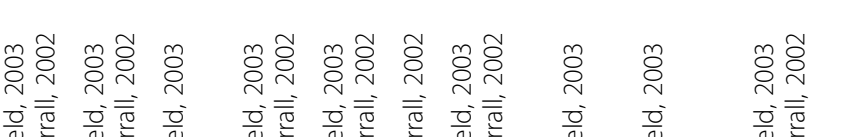

政

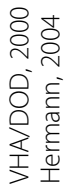

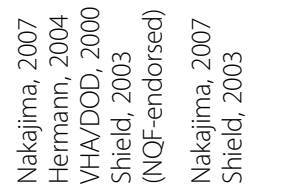

享蓆

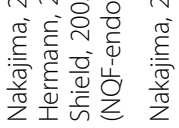
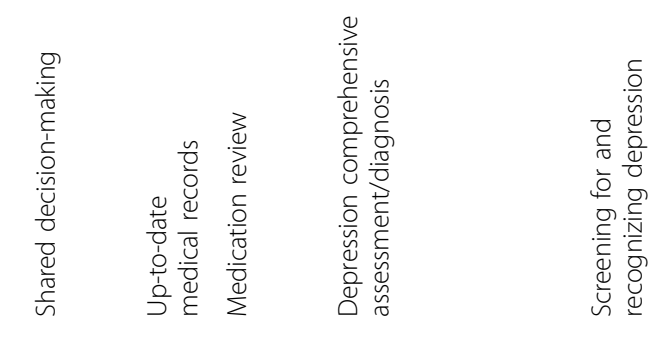

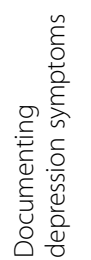

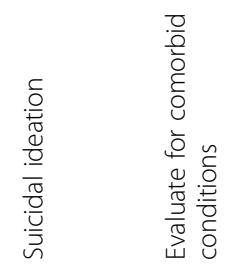




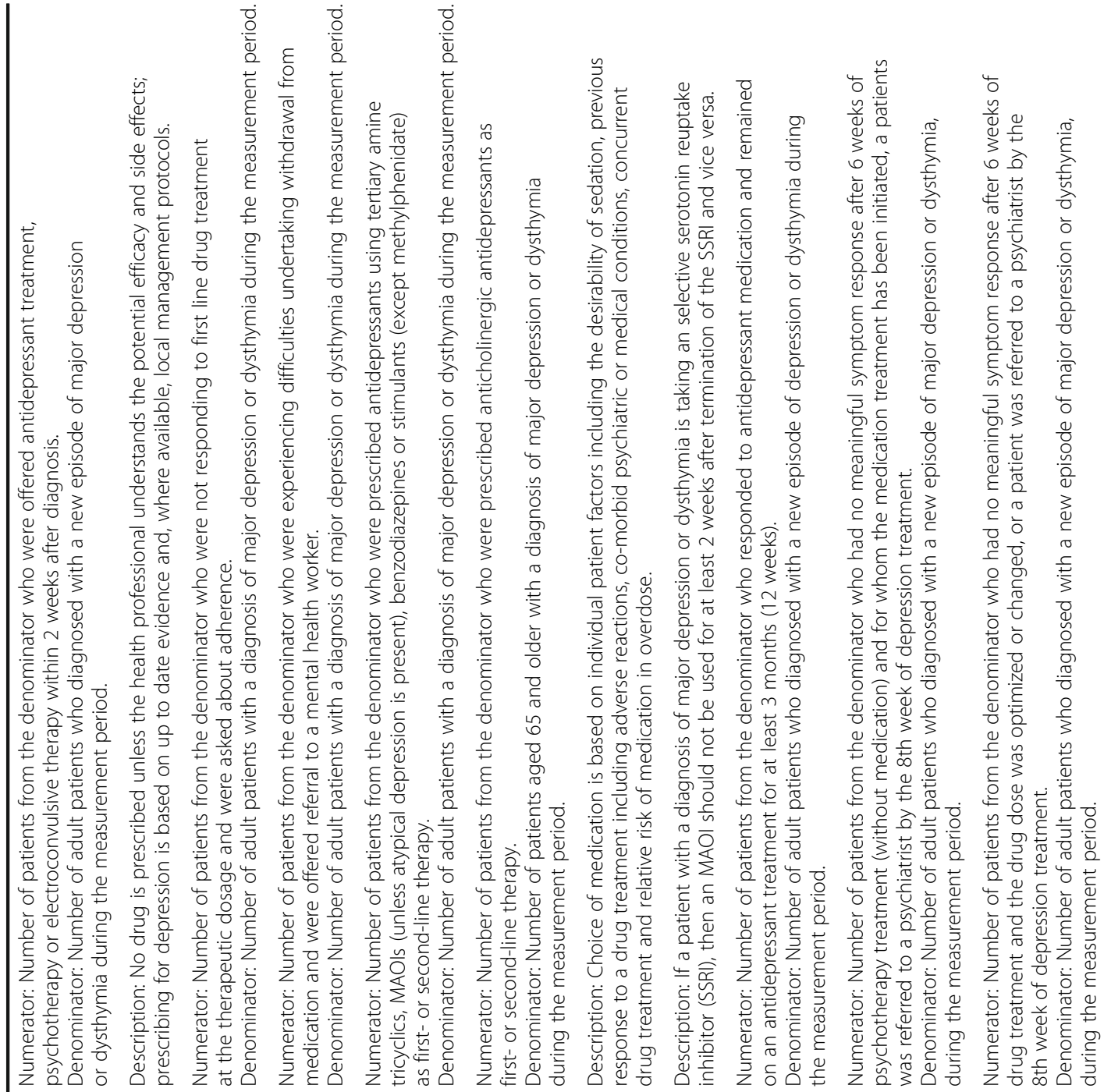

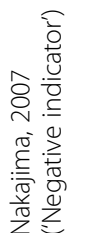
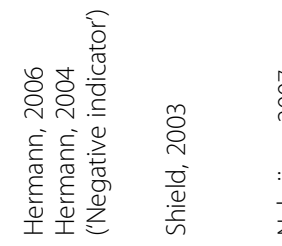

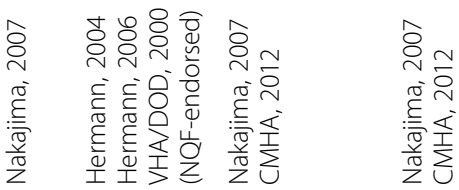

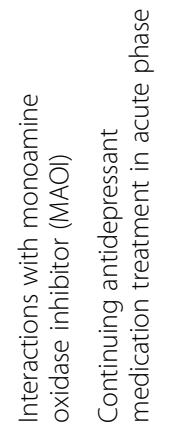



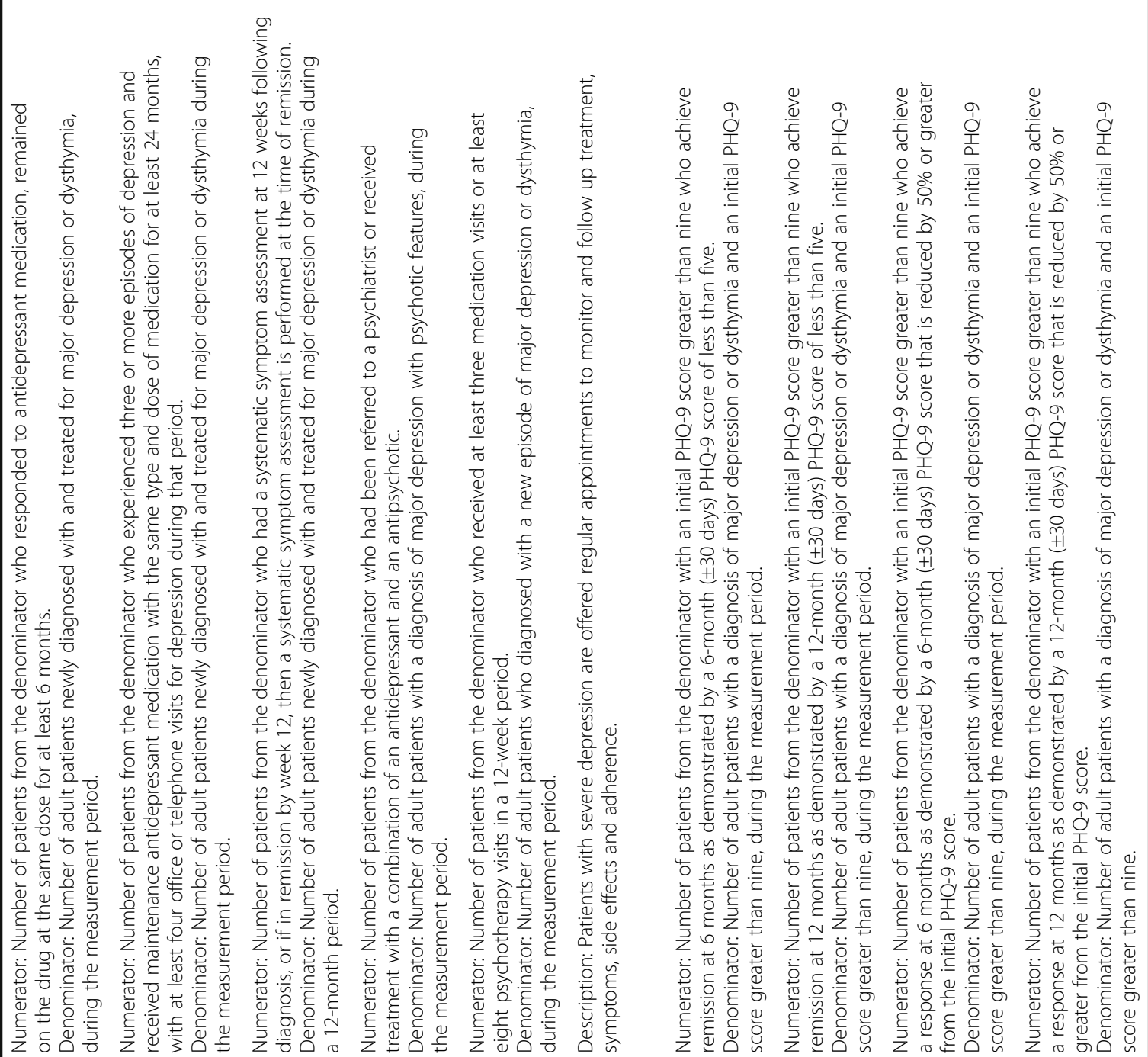

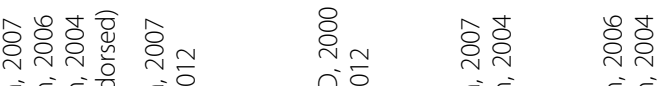

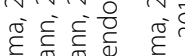

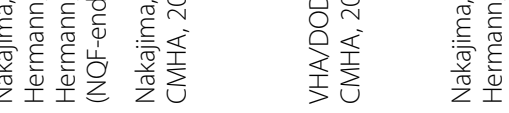

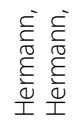

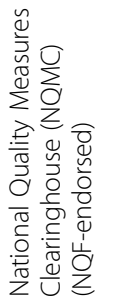

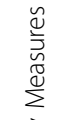

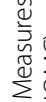
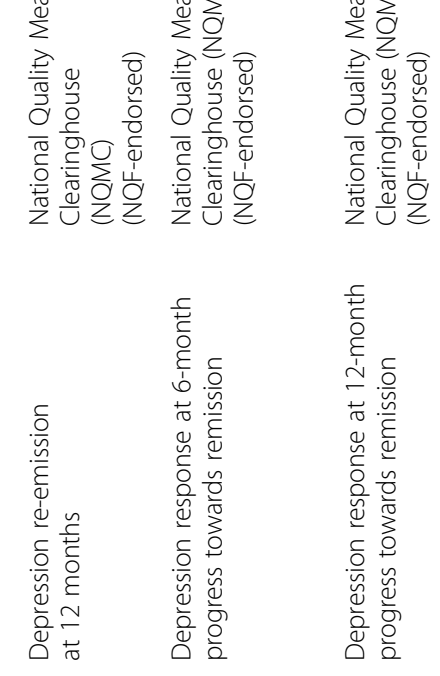
We identified a few 'negative' or 'do not use' indicators, including the use of anticholinergic or tetracyclic antidepressants, benzodiazepines and MAO inhibitors as firstor second-line therapy in older adults with depression.

Outcome indicators identified in this study related to the reduction in the number and severity of depressive symptoms that serve as a marker of wellness of patients with depression. We observed that a limited number of outcome indicators were developed for evaluation of care for depression. Overall, reasons for the small number of outcome indicators may be the limited scientific evidence linking structure and process to outcomes of depression care or perhaps the length of time it takes to assess outcomes due to the often long-term and fluctuating nature of depression or lack of understanding of what meaningful outcomes could/should be measured.

We identified a comprehensive list of quality indicators, including structure, process and outcome indicators. Mainz et al. stated that, although the healthcare providers might need detailed information about the process of depression care for quality improvement purposes, payers of the care and consumers might be more interested in structure and outcomes of the care [20]. Therefore, a combination of structure, process and outcome indicators might be most suitable for measuring the quality of care for depression in primary care settings, and this study provides a useful framework for continued use as this field presumably grows.

Despite the growing interest in assessing the quality of care for depression, there has been little evaluation of the quality of care for depression in primary care settings [11, 24]. For instance, Duhoux and colleagues [24] performed a systematic review of quality indicators for depression treatment in primary care. The authors of this study aimed to systematically review indicators for measuring the quality of depression treatment in primary care related to pharmacotherapy, psychotherapy or educating patients about depression.

They found that most studies used rudimentary indicators to measure the quality of depression treatment, the studies differed greatly with respect to the methods used and most studies revealed that a large proportion of people with depression do not receive minimally adequate treatment in primary care settings [24]. In contrast to the previous studies, the main strength of the present systematic review is that all included studies developed quality indicators using rigorous methods, by combining a systematic literature search/developing indicators from clinical guidelines with appraisal of candidate indicators using expert panel opinion.

Overall, the present systematic review revealed poor reporting of the methods used for developing quality indicators that complicated assessment of the methodological rigour and quality of the studies.

The assessment and monitoring of care quality can be achieved by using quality indicators which are based on standards of care and the best available evidence [20]. Data generated from these measures can be used to assess past performance, identify suboptimal practices and plan improvements. To this end, studies on development of quality indicators should be periodically updated to align with current standards of care. The literature suggests that quality indicators cannot be transferred from one country to another without a prior validation, and often translation, to take into account variations in clinical practice and professional culture [56-58].

The majority of included studies were obtained from the USA or the UK. When selecting healthcare indicators to be used locally, it is important to ensure that they reflect local circumstances and that they can be used to develop local standards of care [56]. In this way, differences in policy priorities, the organization of healthcare system and clinical practice can be addressed.

The feasibility of indicator measurement is another important consideration. It was identified that indicators were assessed in the studies included in this review. Quality indicators identified in this review utilized three common sources of data: secondary data (administrative databases), clinical data (medical records) and survey data.

It is well established that depression is associated with a wide range of chronic conditions, including diabetes, cardiovascular disease, cancer and arthritis, and that it has a negative impact on the outcomes of these conditions [8-10]. However, the methodology to measure quality of care for diabetes patients with multiple chronic conditions has been poorly developed. Therefore, a multidisciplinary expert panel was recruited from across Canada to critically appraise the resulted quality indicators and select the appropriate set of quality indicators for evaluating care for patients with depression comorbid with other chronic conditions. It will be reported in a separate manuscript.

\section{Limitations}

As demonstrated in this study, relatively little rigorous research has been done to develop quality indicators to assess the quality of primary care for depression. However, our intention to include only indicators that have been developed through an evidence-based approach, including a combination of literature search with expert panel opinion, may have led to the exclusion of some indicators that were developed using other approaches. Our literature search was restricted to studies published 
in English that omits potentially relevant publications in other languages.

The AIRE instrument that was used to assess the quality of the included studies is mainly focused on the indicator development process. We may underestimate the methodological quality of some studies, because the information related to the indicator development process was not always described within the articles. We tried to track down additional information in the literature about the development process of quality indicators, but we were able to get relevant additional information only for three sets of quality indicators. Due to time constraints, we did not contact any organization/author to elicit any additional information. The study results indicate the need for further development of quality indicators with detailed methodological specifications for monitoring and accurate assessment of the care for adults with depression in primary care settings.

Overall, we conclude that evidence-based and valid quality indicators for assessing quality of primary care for depression are scarce, but the identified set of indicators address multiple dimensions of depression care and provide an excellent starting point for further development. As the disease burden of depression is high, and much of it is presented clinically to general practitioners, incorporation of these indicators to routine primary care practice is recommended. Periodic evaluation reports of primary care for depression can be useful to monitor performance and serve to evaluate effectiveness of depression care among a general adult population.

Quality indicators should be valid and sensitive to the changes they are intended to detect and should be linked to improving patient outcomes [20]. There is a need to develop specific structure, process and outcome measures for people with depression by engaging clinicians, patients and families in the identification of meaningful measures and then determining how they could be collected systematically. Future research is required to implement the identified set of quality indicators in this study and to examine the association between identified structures and processes and depression care outcomes.

\section{Additional files}

Additional file 1: Search strategies. (DOCX $31 \mathrm{~kb}$ )

Additional file 2: AIRE instrument. (DOCX $30 \mathrm{~kb}$ )

Additional file 3: PRISMA checklist. (PDF $176 \mathrm{~kb}$ )

\section{Abbreviations}

AIRE: Appraisal of Indicators through Research and Evaluation; NQMC: National Quality Measures Clearinghouse; NQF: National Quality Forum; RAND Health Corporation: Research and Development Health Corporation; ACOVE: Assessing Care of Vulnerable Elders; VHA/DOD: Veterans Health Administration Department of Defence; OECD: Organisation for
Economic Co-operation and Development; CMHA: Canadian Mental Health Association; AHRQ: Agency for Healthcare Research and Quality; MAOls: Monoamine oxidase inhibitors

\section{Funding}

This work was supported by a research grant from a Canadian Institute for Health Research Community-Based Primary Health Care Team Grant (\#495120). There are no other sources of support. The funders had no role in the study design, data collection and analysis, decision to publish or preparation of the manuscript.

\section{Availability of data and materials}

The datasets supporting the conclusions of this article are included within the article and supporting material.

\section{Authors' contributions}

YM and WPW substantially contributed to the conception, analysis and interpretation of the data for the work and to the drafting of the work. YS, $J B, K K$ and $B L$ substantially contributed to the analysis and interpretation of the data for the work. YP drafted the manuscript. YP and WPW revised the drafting of the work critically for important intellectual content. All authors contributed to the final approval of the version to be published and are in agreement to be accountable for all aspects of the work and in ensuring that questions related to the accuracy or integrity of any part of the work are appropriately investigated and resolved. All authors read and approved the final manuscript.

Ethics approval and consent to participate

Ethics approval and consent to participate is not applicable. No human data involved.

\section{Consent for publication}

Consent for publication is not applicable. The manuscript contains no individual person's data.

\section{Competing interests}

The authors declare that they have no competing interests.

\section{Publisher's Note}

Springer Nature remains neutral with regard to jurisdictional claims in published maps and institutional affiliations.

\section{Author details}

${ }^{1}$ Institute of Health Policy, Management and Evaluation, University of Toronto, 155 College Street, 4th Floor, Toronto, Ontario M5T 3M6, Canada. ${ }^{2}$ Toronto Health Economics and Technology Assessment (THETA) Collaborative, Toronto General Hospital Research Institute, University Health Network, 200 Elizabeth Street, 10th Floor, Toronto, Ontario M5G 2C4, Canada. ${ }^{3}$ Dalla Lana School of Public Health, University of Toronto, 155 College Street, 4th Floor, Toronto M5T 3M6, Ontario, Canada. ${ }^{4}$ Lunenfeld Tanenbaum Research Institute, Sinai Health System, 1 Bridgepoint Drive, 14 St. Matthews Road, Toronto, Ontario M4M 2B5, Canada. ${ }^{5}$ Sunnybrook Health Sciences Centre, University of Toronto, 2075 Bayview Ave., Room H4 79, Toronto, ON M4N 3M5, Canada. ${ }^{6}$ Institute for Clinical Evaluative Sciences, Toronto, Canada.

${ }^{7}$ Toronto Rehabilitation Institute, Toronto, Canada.

Received: 21 December 2016 Accepted: 20 June 2017

Published online: 03 July 2017

References

1. Buchanan D, Tourigny-Rivard MF, Cappeliez P, Frank C, Janikowski $P$, Spanjevic L, Malach FM, Mokry J, Flint A, Herrmann N. National guidelines for seniors' mental health: the assessment and treatment of depression. Can J Geriatr. 2006;5(2 Suppl):S52-8.

2. Blazer DG, Hybels CF, Pieper CF. The association of depression and mortality in elderly persons: a case for multiple, independent pathways. J Gerontol A Biol Sci Med Sci. 2001;56(8):M505-9.

3. Unutzer J, Patrick DL, Diehr P, Simon G, Grembowski D, Katon W. Quality adjusted life years in older adults with depressive symptoms and chronic medical disorders. Int Psychogeriatr. 2000;12(1):15-33.

4. Blazer DG. Depression in late life: review and commentary. J Gerontol A Biol Sci Med Sci. 2003;58(3):249-65. 
5. Greenberg PE, Fournier AA, Sisitsky T, Pike CT, Kessler RC. The economic burden of adults with major depressive disorder in the United States (2005 and 2010). J Clin Psychiatry. 2015;76(2):155-62.

6. Kessler RC, Avenevoli S, Costello J, Green JG, Gruber MJ, McLaughlin KA Petukhova M, Sampson NA, Zaslavsky AM, Merikangas KR. Severity of 12-month DSM-IV disorders in the national comorbidity survey replication adolescent supplement. Arch Gen Psychiatry. 2005;69(4):381-9.

7. Statistics Canada. Canadian Community Health Survey 2009/2010_annual component. Ottawa: Statistics Canada; 2011.

8. Moussavi S, Chatterji S, Verdes E, Tandon A, Patel V, Ustun B. Depression, chronic diseases, and decrements in health: results from the World Health Surveys. Lancet. 2007;370(9590):851-8.

9. Katon WJ. The comorbidity of diabetes mellitus and depression. Am J Med. 2008;121(11 Suppl 2):S8-15.

10. Barnett K, Mercer SW, Norbury M, Watt G, Wyke S, Guthrie B. Epidemiology of multimorbidity and implications for health care, research, and medical education: a cross-sectional study. Lancet. 2012:380(9836):37-43.

11. Campbell SM, Braspenning J, Hutchinson A, Marshall M. Research methods used in developing and applying quality indicators in primary care. BMJ. 2003;326(7393):816-9.

12. Wittchen $\mathrm{HU}$, Holsboer F, Jacobi F. Met and unmet needs in the management of depressive disorder in the community and primary care: the size and breadth of the problem. J Clin Psychiatry. 2001;62 Suppl 26:23-8.

13. Institute of Medicine (US). Committee on the future of primary care: America's health in a new era. Washington: National Academy Press; 1996

14. Kilbourne AM, Schulberg HC, Post EP, Rollman BL, Belnap BH, Pincus HA. Translating evidence-based depression management services to community-based primary care practices. Milbank Q. 2004;82(4):631-59.

15. Young AS, Klap R, Sherbourne CD, Wells KB. The quality of care for depressive and anxiety disorders in the United States. Arch Gen Psychiatry. 2001;58(1):55-61.

16. Smolders $M$, Laurant $M$, Verhaak $P$, Prins $M$, van Marwijk $H$, Penninx B, Wensing M, Grol R. Which physician and practice characteristics are associated with adherence to evidence-based guidelines for depressive and anxiety disorders? Med Care. 2010;48:240-48.

17. Mallen C, Peat G. Screening older people with joint pain for depression in primary care. Br J Gen Pract. 2006;58:687-92.

18. Abrahamyan $L$, Boom N, Donovan LR, Tu JV. An international environmental scan of quality indicators for cardiovascular care. Can J Cardiol. 2012;28(1):110-8.

19. Harteloh PP. The meaning of quality in health care: a conceptual analysis. Health Care Anal. 2003;11(3):259-67.

20. Mainz J. Defining and classifying clinical indicators for quality improvement. Int J Qual Health Care. 2003;15(6):523-30.

21. Donabedian A. Evaluating the quality of medical care. Milbank Meml Fund Q. 1966:44:166-206.

22. Donabedian A. The quality of care. How can it be assessed? 1988. Arch Pathol Lab Med. 1997;121(11):1145-50.

23. Campbell SM, Hann M, Hacker J, Durie A, Thapar A, Roland MO. Quality assessment for three common conditions in primary care: validity and reliability of review criteria developed by expert panels for angina, asthma and type 2 diabetes. Qual Saf Health Care. 2002;11(2):125-30.

24. Duhoux A, Louise F, Matthew M. Quality indicators for depression treatment in primary care: a systematic literature review. Curr Psychiatry Rev. 201 1;7:104-37.

25. Fitch K, Bernstein SJ, Burnand B, LaCalle JR, Lazaro P, McDonnell J, Varder JP, Kahan JP. The RAND/UCLA appropriateness method user's manual. Santa Monica: RAND Corporation; 2001.

26. Stelfox HT, Straus SE. Measuring quality of care: considering conceptual approaches to quality indicator development and evaluation. J Clin Epidemiol. 2013;66(12):1328-37.

27. Higgins JP, Deeks JJ. Selecting studies and collecting data. Higgins J, Green S, editors. Cochrane Handbook for Systematic Reviews of Interventions: Cochrane Book Series. England: John Wiley \& Sons Ltd; 2008.

28. Iovieno N, Tedeschini E, Bentley KH, Evins AE, Papakostas Gl. Antidepressants for major depressive disorder and dysthymic disorder in patients with comorbid alcohol use disorders: a meta-analysis of placebocontrolled randomized trials. J Clin Psychiatry. 2011;72(8):1144-51.

29. Levkovitz Y, Tedeschini E, Papakostas Gl. Efficacy of antidepressants for dysthymia: a meta-analysis of placebo-controlled randomized trials. J Clin Psychiatry. 2011;72(4):509-14.

30. Pedrelli P, lovieno N, Vitali M, Tedeschini E, Bentley KH, Papakostas Gl. Treatment of major depressive disorder and dysthymic disorder with antidepressants in patients with comorbid opiate use disorders enrolled in methadone maintenance therapy: a meta-analysis. J Clin Psychopharmacol. 2011;31(5):582-6.

31. Patten SB, Kennedy SH, Lam RW, O'Donovan C, Filteau MJ, Parikh SV, Ravindran AV. Canadian Network for Mood and Anxiety Treatments (CANMAT) clinical guidelines for the management of major depressive disorder in adults. I. Classification, burden and principles of management. J Affect Disord. 2009;117 Suppl 1:S5-14.

32. Lam RW, Mclntosh D, Wang J, Enns MW, Kolivakis T, Michalak EE, Sareen J, Song WY, Kennedy SH, MacQueen GM, Milev RV, Parikh SV, Ravindran AV. Canadian Network for Mood and Anxiety Treatments (CANMAT) 2016 clinical guidelines for the management of adults with major depressive disorder: section 1. Disease burden and principles of care. Can J Psychiatry. 2016;61(9):510-23.

33. de Koning J, Smulders A, Klazinga NS. The Appraisal of Indicators through Research and Evaluation (AIRE) instrument. Amsterdam: Academic Medical Center; 2006. doi:10.1111/acem.12591.

34. Smeulers M, Verweij L, Maaskant JM, de Boer M, Krediet CT, Nieveen van Dijkum EJ, Vermeulen H. Quality indicators for safe medication preparation and administration: a systematic review. PLoS One. 2015;10(4):e0122695.

35. Strudwick K, Nelson M, Martin-Khan M, Bourke M, Bell A, Russell T. Quality indicators for musculoskeletal injury management in the emergency department: a systematic review. Acad Emerg Med. 2015;22(2):127-41.

36. Pasman HR, Brandt HE, Deliens L, Francke AL. Quality indicators for palliative care: a systematic review. J Pain Symptom Manage. 2009:38(1):145-56.

37. Donabedian A. Methods for deriving criteria for assessing the quality of medical care. Med Care Rev. 1980;37(7):653-98.

38. Donabedian A. The quality of care. How can it be assessed? Arch Pathol Lab Med. 1988;121(11):1145-50.

39. Hogg W, Rowan M, Russell G, Geneau R, Muldoon L. Framework for primary care organizations: the importance of a structural domain. Int J Qual Health Care. 2008;20(5):308-13.

40. Orwin RG. In : Cooper H, Hedges LV (eds.) The handbook of research synthesis. Russell Sage Foundation NY. 1994:150-51.

41. Nakajima GA, Wenger NS. Quality indicators for the care of depression in vulnerable elders. J Am Geriatr Soc. 2007;55 Suppl 2:S302-11.

42. Hermann RC, Palmer H, Leff S, Shwartz M, Provost S, Chan J, Chiu WT, Lagodmos G. Achieving consensus across diverse stakeholders on quality measures for mental healthcare. Med Care. 2004;42(12):1246-53.

43. Veterans Health Administration/Department of Defense. VHA/DOD performance measures for the management of major depressive disorder in adults, version 2.0. Washington; 2000.

44. Hermann RC, Mattke S, Somekh D, Silfverhielm H, Goldner E, Glover G, Pirkis J, Mainz J, Chan JA. Quality indicators for international benchmarking of mental health care. Int J Qual Health Care. 2006;18 Suppl 1:31-8.

45. Canadian Mental Health Association. Improving primary care mental health services. Results of a national quality care project. Published February, 2012. https://www.cmha.bc.ca. Accessed 28 Oct 2014.

46. Shield T, Campbell S, Rogers A, Worrall A, Chew-Graham C, Gask L. Quality indicators for primary care mental health services. Qual Saf Health Care. 2003;12(2):100-6.

47. Worrall A, Rees A, Richards A, Rix S, Wright C, Lelliott P. The development of a set of quality indicators to evaluate services for people with depression. J of Mental Health. 2002;11(6):677-84.

48. Medicine lo. Toward quality measures for population health and the leading health indicators. Washington, DC: The National Academies Press; 2013. doi:10.17226/18339.

49. Patel MM, Brown JD, Croake S, Lewis R, Liu J, Patton L, Potter DE, Scholle $\mathrm{SH}$. The current state of behavioral health quality measures: where are the gaps? Psychiatr Serv. 2015;66(8):865-71.

50. Snow V, Lascher S, Mottur-Pilson C. Pharmacologic treatment of acute major depression and dysthymia. American College of Physicians-American Society of Internal Medicine. Ann Intern Med. 2000;132(9):738-42.

51. (NQMC) NQMC. Adult depression in primary care: percentage of patients who have had a response to treatment at six months (+/- 30 days) after diagnosis or initiating treatment, e.g., have had a PHQ-9 score decreased by $50 \%$ from initial score at six months (+/- 30 days). Rockville MD: Agency for Healthcare Research and Quality (AHRQ).

52. (NQMC) NQMC. Adult depression in primary care: percentage of patients who have had a response to treatment at 12 months (+/- 30 days) after diagnosis or initiating treatment, e.g., have had a PHQ-9 score decreased by 
50\% from initial score at 12 months (+/- 30 days). Rockville MD: Agency for Healthcare Research and Quality (AHRQ).

53. (NQMC) NQMC. Adult depression in primary care: percentage of patients who have reached remission at six months (+/- 30 days) after diagnosis or initiating treatment, e.g., have any PHQ-9 score less than 5 after six months (+/- 30 days). Rockville MD: Agency for Healthcare Research and Quality (AHRQ).

54. (NQMC) NQMC. Adult depression in primary care: percentage of patients who have reached remission at 12 months ( $+/-30$ days) after initiating treatment, e.g., had a PHQ-9 score less than 5 after 12 months (+/- 30 days). Rockville MD: Agency for Healthcare Research and Quality (AHRQ).

55. Boulkedid R, Abdoul H, Loustau M, Sibony O, Alberti C. Using and reporting the Delphi method for selecting healthcare quality indicators: a systematic review. PLoS One. 2011;6(6):e20476.

56. Marshall MN, Shekelle PG, McGlynn EA, Campbell S, Brook RH, Roland MO. Can health care quality indicators be transferred between countries? Qual Saf Health Care. 2003;12(1):8-12.

57. Steel N, Melzer D, Shekelle PG, Wenger NS, Forsyth D, McWilliams BC. Developing quality indicators for older adults: transfer from the USA to the UK is feasible. Qual Saf Health Care. 2004;13(4):260-4.

58. Kroger E, Tourigny A, Morin D, Cote L, Kergoat MJ, Lebel P, Robichaud L, Imbeault S, Proulx S, Benounissa Z. Selecting process quality indicators for the integrated care of vulnerable older adults affected by cognitive impairment or dementia. BMC Health Serv Res. 2007;7:195.

\section{Submit your next manuscript to BioMed Central and we will help you at every step:}

- We accept pre-submission inquiries

- Our selector tool helps you to find the most relevant journal

- We provide round the clock customer support

- Convenient online submission

- Thorough peer review

- Inclusion in PubMed and all major indexing services

- Maximum visibility for your research

Submit your manuscript at www.biomedcentral.com/submit 